\title{
Gastroenteritis outbreaks in elderly homes in the east of France during winter 2009/10: aetiology research for a series of 37 outbreaks
}

F Thouillot ${ }^{1}$, C Delhostal $^{2}$, C Edel $^{2}$, A Bettinger ${ }^{3}$, P Pothier $^{4}$, K Ambert-Balay $^{4}$, C Meffre $^{1}$, S Alsibai (sophie.alsibai@ars.sante.fr) ${ }^{1}$

1. Eastern Regional Office (Cire-Est) of the French Institute for Public Health Surveillance (Institut de Veille Sanitaire, InVS), Nancy, France

2. Regional Agency for Public Health of Alsace (Agence Régionale de Santé d’Alsace), Strasbourg, France

3. Alsatian Regional Association against Nosocomial Infections (Antenne Régionale Alsace de Lutte contre les Infections Nosocomiales - ARALIN), Strasbourg France

4. French National Reference Centre for Enteric Viruses, Dijon, France

Citation style for this article:

Thouillot F, Delhostal C, Edel C, Bettinger A, Pothier P, Ambert-Balay K, Meffre C, Alsibai S. Gastroenteritis outbreaks in elderly homes in the east of France during winter 2009/10: aetiology research for a series of 37 outbreaks.

Euro Surveill. 2012;17(9):pii=20103. Available online: http://www.eurosurveillance.org/ViewArticle.aspx?Articleld=20103

Article published on 1 March 2012

Although acute gastroenteritis is a common cause of morbi-mortality in care homes, there is no national surveillance system in France except for food-borne gastroenteritis. Since 2008, a specific surveillance system has been operating in nursing homes in Alsace, a region in eastern French. In the winter season $2009 / 10$ we had the opportunity to study 37 outbreaks, collecting data on attack rate, duration and aetiology as well as epidemic management in nursing homes. We noticed the responsiveness of the institutions, with a mean period of 1.6 days between the onset of first symptoms and the implementation of management measures (95\% confidence interval $(\mathrm{Cl})$ : 1.0-2.2). One or several stool samples were taken in 27 of the 37 described outbreaks. The only pathogen detected was norovirus, and the positive samples were from outbreaks with a very typical pattern: vomiting in 36 of the outbreaks, a high average attack rate of $36.8 \%(95 \% \mathrm{Cl}: 31.5-42.2)$ and a short average duration of 8.9 days ( $95 \% \mathrm{Cl}: 5.8-7.0$ ). No severe cases, hospitalisations or deaths were reported. The high frequency of norovirus isolation indicated that systematic bacteriological analysis in local laboratories is not cost-effective. Consequently, Cire Est recommends to test for bacteria and viruses only in cases presenting with fever or atypical symptoms. Nevertheless, Cire Est also recommends to continue sending stool samples to the French National Centre for enteric viruses, more for the benefit of the virological surveillance programme than for diagnostic purposes.

\section{Introduction}

Gastroenteritis is one of the most frequent causes of infectious disease outbreaks during winter in nursing homes, on a par with acute respiratory infections. Impaired immune function, chronic diseases and communal living are factors that make the elderly particularly vulnerable to these infections. In addition to the individual consequences of a gastroenteritis episode for elderly people [1], the epidemic burden is heavy, especially for viral infections that can reach high attack rates, leading to significant disorganisation in the management of such institutions. Although the aetiology is not investigated very often, it appears that norovirus, a major cause of gastroenteritis worldwide $[2,3]$, is frequently involved $[4,5]$.

There is no surveillance system for gastroenteritis in France except for food-borne outbreaks. Therefore, the available information about gastroenteritis outbreaks in nursing homes is limited, despite their frequency and the different management strategies they required. However, in the eastern French region of Alsace, a surveillance system of gastroenteritis outbreaks during the winter season has been in operation in nursing homes since 2008. This system aims at supporting nursing homes that are experiencing a gastroenteritis outbreak and at improving their responsiveness in implementing management measures to mitigate morbi-mortality associated with the outbreak. Each gastroenteritis outbreak that occurs in a nursing home has to be notified to health authorities and recorded in a database.

This article describes gastroenteritis outbreaks which occurred in Alsace during the winter season 2009/10. Based on our descriptive analysis, we propose recommendations to adapt aetiology research for nursing homes in future gastroenteritis outbreaks.

\section{Methods}

\section{Population studied}

The region Alsace is divided in two départements, BasRhin (département 67) and Haut-Rhin (département 
68). In our study, we included all residents from the 200 nursing homes of Alsace, as well as those members of staff who were in direct contact with residents; we excluded administrative and logistic staff from our data collection.

\section{Gastroenteritis definition}

Gastroenteritis was defined as the sudden onset of at least two episodes of vomiting or two episodes of diarrhoea during a 24-hour period. Diarrhoea was defined as at least two thick liquid or watery stools above what is normal for the resident or employee within a 24-hour period [6].

\section{Gastroenteritis outbreak definition}

With the first national recommendations report about gastroenteritis outbreaks in nursing homes still under review [6], a quantitative definition does not yet exist in France. The French Institute for Public Health Surveillance (InVS) recommended defining an outbreak of gastroenteritis as an event with more patients (residents or staff) than usual in predetermined places and time periods present gastroenteritis, and there appears to be an epidemiological link relating the patients (same meals and same activities).

In French nursing homes, the medical coordinator or the nursing officer is authorised to report the outbreaks.

\section{Data collection}

Data on food-borne outbreaks were not collected, because these are notified in a specific French surveillance system. According to that database, no food-borne outbreak was declared during the winter 2009/10 in nursing homes in Alsace.

The gastroenteritis outbreak surveillance protocol was designed by the Eastern Regional Office of the InVS (Cire Est). Preliminary actions to increase the nursing homes' awareness of the new surveillance programme have been conducted since 2008 in association with the departmental health authorities. Managers of the establishments were invited to local information meetings presenting the subject and to the Regional Day of Hygiene, a well-known local seminar. They received by post or email all tools for the surveillance system (a template for an epidemic curve, notification forms, instructions on how to notify, etc) and advice on how to manage the outbreaks using these tools.

Once the protocol was introduced to the nursing homes, each facility developed an internal procedure to detect and declare gastroenteritis outbreaks and to ensure prompt and appropriate management measures and investigation of the aetiology of the outbreaks.

Cire Est provided a standard form for collecting the following data:

- Place where the outbreak occurred,

- Date of onset of symptoms,
- Date of reporting to public health authorities,

- Diagnosis and clinical signs (predominant symptoms in the outbreak),

- Total number of residents and number of ill residents,

- Number of staff in direct contact with residents and number of sick staff,

- Number of severe cases (deaths or hospitalisations),

- Date of first stool sample taken per outbreak,

- Results of aetiology analysis (laboratory identification of the causal agent),

- Date of implementation of management measures,

- Alerted partners (Regional Agency for Public Health, operational hygiene teams in the establishments where this exists, committees for nosocomial infections, e.g. Agence Régionale de Lutte contre les Infections Nosocomiales)

- Closing date of the folder (recovery date of the last resident).

All data were collected and entered in a single Excel file by a qualified public health officer from the Regional Agency for Public Health of Alsace (representing the local public health authorities), and sent to the Cire Est to be analysed.

\section{Study period}

Outbreaks of gastroenteritis were recorded in our database from the beginning of November 2009 (week 452009 ) to the end of May 2010 (week 21 2010). This study period corresponded to the time when gastroenteritis outbreaks usually occur in France [7]. Periods were calculated starting from the date of symptom onset of the first case. The end of the outbreak was the date of recovery of the last case.

\section{Aetiology}

Once an outbreak occurred it was recommended that the nursing home should send stool samples (three to five per outbreak if possible) to the local private or public diagnostic laboratory. A bacterial analysis was conducted along with a first level viral analysis (adenovirus and rotavirus). If results were negative, samples had to be sent to the French National Reference Centre for enteric viruses for complementary viral analysis (especially norovirus).

\section{Statistical analysis}

A descriptive analysis was performed using EpiData Analysis.

\section{Results}

During the study period, 37 outbreaks of gastroenteritis in nursing homes were reported to the Regional Agency for Public Health of Alsace and included in our study. Twenty-two occurred in Bas-Rhin (département 67 ) and 15 in Haut-Rhin (département 68).

Spatiotemporal distribution of the outbreaks Figure 1 shows the distribution of the outbreaks by département during the study period. 
From week 45 to week 52 of 2009 no outbreaks were reported to the Alsatian health authorities. From the last week of 2009 to the week 8 of 2010, outbreaks were reported at a variable rate of between zero and two outbreaks per week in either département.

In Bas-Rhin, three outbreaks were reported during week 92010 and five outbreaks during week 10 2010, which constituted a significant increase. From week 11 2010 to the end of the study period, the number of outbreaks decreased and returned to the level of incidence observed before the epidemic period which began in week 522009.

In Haut-Rhin, no significant increase in the number of outbreaks was observed. From week 12010 to week 14 2010, a stable level of incidence was observed with no more than two outbreaks a week.

Attack rates

Attack rates were calculated for the residents of all 37 outbreaks. Staff in contact with residents was affected in 30 of the 36 outbreaks for which information was available.

The observed average attack rate among residents was $36.8 \%$ (95\% confidence interval (CI): 31.5-42.2). It ranged between $4 \%$ and $70 \%$ for the 37 outbreaks. We also calculated average attack rates for staff in those 30 outbreaks which affected members of staff who were in contact with residents. The observed average staff attack rate was $20.9 \%$ (95\% Cl: $14.5-27.7)$. It ranged between $3 \%$ and $73 \%$ for the 30 outbreaks taken into account.

\section{Symptoms}

Four types of symptoms were reported in association with the outbreaks. Diarrhoea was described in all 37 registered outbreaks, and vomiting was reported in 36 of them. Nausea and fever were minor symptoms and reported in six and two outbreaks, respectively). No severe cases were reported (hospitalisations or death).

\section{FIGURE}

Distribution of gastroenteritis outbreaks in nursing homes, by week, November 2009-May 2010, Alsace, France $(n=37)$

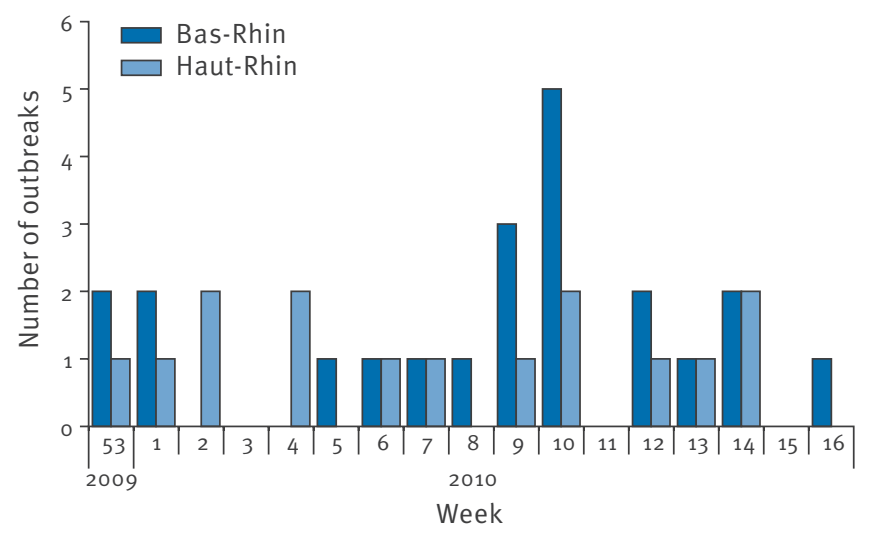

Aetiology

No samples were available for 10 outbreaks. In the other $\mathbf{2 7}$ outbreaks, between one and five stool samples per outbreak were collected by the nursing homes regardless of the attack rate.

Stool samples from three outbreaks were directly analysed and found positive by the reporting nursing home, using a norovirus rapid diagnosis test; the genogroup was not specified. All collected samples of the 24 other outbreaks were sent to local laboratories for bacterial analysis and first level viral analysis (adenovirus and rotavirus). All of them were negative. Our recommendation was to send all negative samples to the French National Reference Centre for complementary viral analysis. Samples from 17 outbreaks were sent: one sample was negative, three were positive for norovirus genogroup I (GI), and 13 were positive for norovirus genogroup II (GII). The results are summarised in Table 1.

Genotyping was performed for the 16 outbreaks for which samples were sent to the French National Reference Centre for Enteric Viruses. The three GI norovirus isolates were of genotype 4. Among the $13 \mathrm{GII}$ norovirus isolates, nine were genotype 4 variant 2010, three were genotype IIb/ II.1, and one was genotype 4 variant $2006 \mathrm{~b}$.

\section{Outbreak management}

Table 2 summarises the reactivity of the nursing homes (notification period, period before the implementation of management measures), and the duration of the outbreaks.

We noticed that the management measures were implemented rapidly, with an average of 1.6 days after the start of the outbreak ( $95 \%$ confidence interval $(\mathrm{CI})$ :

\section{TABLE 1}

Microbiological analyses, gastroenteritis outbreaks in nursing homes, November 2009-May 2010, Alsace, France $(n=37)$

\begin{tabular}{|c|c|}
\hline & $\begin{array}{l}\text { Number of } \\
\text { outbreaks }\end{array}$ \\
\hline No stool sample taken & 10 \\
\hline $\begin{array}{l}\text { Negative bacteriology and negative first level viral } \\
\text { research }\end{array}$ & 7 \\
\hline $\begin{array}{l}\text { Negative virology } \\
\text { (French National Reference Center for Enteric Viruses) }^{\mathrm{b}}\end{array}$ & 1 \\
\hline $\begin{array}{l}\text { Positive for norovirus, no genotyping } \\
\text { (rapid diagnosis test at nursing home) }\end{array}$ & 3 \\
\hline $\begin{array}{l}\text { Positive for norovirus G II } \\
\text { (French National Reference Center for Enteric Viruses) }^{\mathrm{b}}\end{array}$ & 13 \\
\hline $\begin{array}{l}\text { Positive for norovirus G I } \\
\text { (French National Reference Center for Enteric Viruses) }^{\text {b }}\end{array}$ & 3 \\
\hline \multicolumn{2}{|l|}{$\begin{array}{l}\text { The stool samples were not sent to the French National } \\
\text { Reference Centre for enteric viruses. }\end{array}$} \\
\hline \multicolumn{2}{|c|}{$\begin{array}{l}\text { The samples were negative in bacterial and the first level viral } \\
\text { diagnostics and therefore sent to the French National Reference } \\
\text { Centre for Enteric Viruses for complementary viral analysis. }\end{array}$} \\
\hline
\end{tabular}


1.0-2.2), and that half of the outbreaks were managed within one day or less. The longest period before implementation of measures was seven days. The outbreaks were reported to the health authorities after an average of 7.9 days (95\% Cl: 4.9-10.6) and lasted an average of 8.9 days ( $95 \% \mathrm{Cl}: 5.8-7.0$ ).

Those nursing homes that observed the recommendations more closely and had shorter delays of outbreak notification and implementation of measures were more likely (Student's t-test, p<0.05) to collect stool samples. All these parameters were independent of the attack rates (chi-square test with Yates correction p<0.05).

\section{Discussion}

From November 2009 to May 2010, 37 gastroenteritis outbreaks were reported to the health authorities in Alsace. Only in Bas-Rhin did the number of outbreaks increase significantly during the first half of March. No bacterial agent was found in the 27 outbreaks for which aetiology research was conducted. Only noroviruses were isolated. The attack rates in residents and staff were high with an average of $36.8 \%(95 \% \mathrm{Cl}: 31.5-$ 42.2) in residents and of $20.9 \%(95 \% \mathrm{Cl}: 14.5-27.7)$ in staff. At least one member of staff was affected in the majority of the reported outbreaks. The most frequent outbreak-associated symptoms were diarrhoea and vomiting.

\section{Late start of gastroenteritis season}

Usually, gastroenteritis winter outbreaks in elderly communities are first noticed in November, at the same time as transmission in the general population begins [7]. In our study, the first outbreak was reported only at the end of December 2009. The same late start was observed among the general population in France by the general practitioner network of the National Institute for Health and Medical Research (Institut National de la Santé et de la Recherche Médicale, INSERM) sentinels.

Seeing as the winter 2009/10 was characterised by the 2009 influenza $A\left(\mathrm{H}_{1} \mathrm{~N}_{1}\right)$ pandemic, which began to decrease during the second half of December [8], we propose two hypotheses that could explain the late start of the norovirus season: (i) Strict hygiene measures taken to control the spread of influenza $A\left(\mathrm{H}_{1} \mathrm{~N}_{1}\right)$

\section{TABLE 2}

Outbreak management parameters, gastroenteritis outbreaks in nursing homes, November 2009-May 2010, Alsace, France $(n=37)$

\begin{tabular}{|l|c|c|c|c|c|}
\hline & Median & Mean & $95 \% \mathrm{Cl}$ & Min & Max \\
\hline Notification period (days) & 5 & 7.92 & {$[4.93-10.6]$} & 0 & 37 \\
\hline $\begin{array}{l}\text { Period for implementing } \\
\text { management measures } \\
\text { (days) }\end{array}$ & 1 & 1.63 & {$[0.99-2.22]$} & 0 & 7 \\
\hline Outbreak duration (days) & 7 & 8.94 & {$[5.84-6.97]$} & 2 & 26 \\
\hline
\end{tabular}

$\mathrm{Cl}$ : confidence interval. pdmog could at the same time have limited gastroenteritis transmission inside nursing homes; (ii) Medical staff focusing on controlling the influenza $A\left(\mathrm{H}_{1} \mathrm{~N}_{1}\right)$ pdmog burden may have been less attentive to gastroenteritis outbreaks notification.

\section{Epidemiological and clinical pattern and outbreak management}

The epidemiological and clinical pattern with high attack rates in residents and staff of $37 \%$ and $21 \%$, respectively, and a high frequency of vomiting was indicative of norovirus infection [9]. This was confirmed by the microbiological tests, which identified norovirus in 19 of the 27 outbreaks for which stool samples were collected. No other bacterial or viral causal agent was found. There was no statistically significant difference in attack rates and clinical features between outbreaks for which aetiology research was or was not done (Student's t-test, p<0.05). We conclude that most of the 37 outbreaks could have been be due to norovirus.

The nursing homes participating in our surveillance system adapted quickly to the task of reporting and managing gastroenteritis outbreaks. The median period for implementing management measures was short (one day). Consequently, the median duration of the outbreaks was short (seven days), in spite of the high attack rates. Norovirus epidemics are usually difficult to control and last longer than other viral or bacterial epidemics. This is due to the contagiousness of these viruses, their persistence in the environment [10], and the fact that they can be excreted after the symptomatic period $[4,9]$. Furthermore, aetiology research was conducted for more than two thirds of the outbreaks, a sign of the readiness of the reporting structures to follow the protocol and to manage the situation correctly.

\section{Aetiology research}

In 16 of the 17 outbreaks for which stool samples were sent to the French National Reference Centre for enteric viruses, norovirus was found. Norovirus is the most common cause of epidemic non-bacterial gastroenteritis worldwide [11-13] and an important cause of gastroenteritis in care facilities for the elderly $[5,9]$. It was the cause of $82.6 \%$ of all viral gastroenteritis outbreaks covered in a review of enteric outbreaks in long-term care facilities from January 1997 to June 2007 [4]. The 2010 variant of norovirus GII.4 was the most frequent causal agent found in our study. Variants of this genotype (GII.4) have emerged in the past decade as the predominant strain worldwide and cause regular outbreaks [14-16].

The clinical symptomatology (high frequency of vomiting) and epidemiology (high attack rates from the very first days) of norovirus outbreaks allow clinical diagnosis without aetiology research. We can question the cost-effectiveness of a systematic stool analysis for diagnostic purposes and especially the necessity of the bacteriological analysis in local laboratories. 
Analysis of this series of gastroenteritis outbreaks made Cire Est change its recommendations on aetiology research. In agreement with the InVS, Cire Est recommend bacterial and first level viral analyses of stool samples in local laboratories exclusively in outbreaks where patients present fever or an atypical clinical picture. When the clinical picture suggests norovirus, stool samples from chosen outbreaks should be sent directly to the French National Reference Centre for enteric viruses as a contribution to virological surveillance. These recommendations refer to the entire year, not only the winter, given that the establishments perform surveillance all year round.

\section{Limitations of the study}

We identified limitations inherent in the data collection. Firstly, symptoms were not collected at the individual level but at the outbreak level. In our database, we were not able to determine the frequency of each symptom among residents or staff, nor their duration. Secondly, staff affected by digestive disorders may not have systematically notified them to employers, possibly because they did not realise they were a potential source of contamination, or because they were worried that sick leave would not be paid [17]. If that was the case, we may have underestimated attack rates among staff. Finally, we cannot exclude a selection bias in our outbreak series. The largest outbreaks or those with more serious symptoms may have been more likely to be notified.

\section{Conclusion}

We can conclude that the nursing homes aware of the surveillance protocol collaborated well with health authorities and respected instructions. Indeed, the outbreaks were rapidly controlled and we collected a sizeable and valuable set of data, including results of the aetiological research for a large proportion of them.

Given the frequency of norovirus implicated as the causative agent in our outbreak series and the obvious clinical pattern, we recommend, as an evolution of the surveillance system, to give up systematic stool collection, and to reserve it for occasions involving fever or atypical clinical pattern. Samples from a small selection of outbreaks would however be sent directly to the National Reference Centre for enteric viruses in order to supply the virological surveillance which aims to describe the national circulation of enteric viruses. and staff of long-term care facilities, Australia. Infect Control Hosp Epidemiol. 2010;31(8):860-3.

6. Haut Conseil de la Santé Publique - Commission spécialisée Maladies transmissibles. Recommandations relatives aux conduites à tenir devant des gastro-entérites aiguës en établissement d'hébergement pour personnes âgées. [Recommendations for measures to be taken for acute gastroenteritides in homes for the elderly]. Paris: Ministèrede la Santé et des Sports; 29 Jan 2010. French. Available from: http://www.hcsp.fr/docspdf/avisrapports/ hcspr20100129_gastro.pdf

7. Carrillo-Santisteve $P$, Ambert-Balay K, Arena C, Poujol I, Caillère N, Delmas G, et al. Epidémies hivernales de gastroentérites aiguës en France, bilan de trois saisons (2006/2007, 2007/2008 et 2008/2009). [Winter outbreaks of acute gastro-enteritis in France: results for three seasons (2006/007, 2007/2008 and 2008/2009)]. Bull Epidémiol Hebd. 2010;31-32:349-52. French. Available from: http://opac.invs. sante.fr/index.php?lvl=bulletin_display\&id=100

8. Institut de Veille Sanitaire (InVS). Point de situation au 29 décembre 2009. Bulletin grippe $A\left(\mathrm{H}_{1} \mathrm{~N}_{1}\right)$. 2009;77. Paris: InVS; 29 Dec 2009.

9. Goller JL, Dimitriadis A, Tan A, Kelly H, Marshall JA. Long-term features of norovirus gastroenteritis in the elderly. J Hosp Infect. 2004;58(4):286-91.

10. Clay S, Maherchandani S, Malik YS, Goyal SM. Survival on uncommon fomites of feline calicivirus, a surrogate of noroviruses. Am J Infect Control. 2006;34(1):41-3.

11. Atmar RL, Estes MK. The epidemiologic and clinical importance of norovirus infection. Gastroenterol Clin North Am. 2006;35(2):275-90, viii.

12. Koch J, Schneider T, Stark K, Schreier E. [Norovirus infections in Germany]. Bundesgesundheitsblatt Gesundheitsforschung Gesundheitsschutz. 2006;49(3):296-309. German.

13. Green KY. The role of human caliciviruses in epidemic gastroenteritis. Arch Virol Suppl. 1997;13:153-65.

14. Lopman B, Vennema H, Kohli E, Pothier P, Sanchez A, Negredo $A$, et al. Increase in viral gastroenteritis outbreaks in Europe and epidemic spread of new norovirus variant. Lancet. 2004;363(9410):682-8.

15. Noel JS, Fankhauser RL, Ando T, Monroe SS, Glass RI. Identification of a distinct common strain of "Norwalklike viruses" having a global distribution. J Infect Dis. 1999;179(6):1334-44.

16. Siebenga JJ, Vennema H, Zheng DP, Vinje J, Lee BE, Pang XL, et al. Norovirus illness is a global problem: emergence and spread of norovirus GII.4 variants, 2001-2007. J Infect Dis. 2009;200(5):802-12.

17. LI J, Birkhead GS, Strogatz DS, Coles FB. Impact of institution size, staffing patterns, and infection control practices on communicable disease outbreaks in New York State nursing homes. Am J Epidemiol. 1996;143(10):1042-9.
References

1. Jones TF. When diarrhea gets deadly: a look at gastroenteritis outbreaks in nursing homes. Clin Infect Dis. 2010;51(8):915-6.

2. Glass RI, Parashar UD, Estes MK. Norovirus gastroenteritis. N Engl J Med. 2009;361(18):1776-85.

3. Tseng CY, Chen CH, Su SC, Wu FT, Chen CC, Hsieh GY, et al. Characteristics of norovirus gastroenteritis outbreaks in a psychiatric centre. Epidemiol Infect. 2010;139(2):275-85.

4. Greig JD, Lee MB. Enteric outbreaks in long-term care facilities and recommendations for prevention: a review. Epidemiol Infect. 2009;137(2):145-55.

5. Kirk MD, Moffatt CR, Hall GV, Becker N, Booy R, Heron L, et al. The burden of infectious gastroenteritis in elderly residents 